\title{
LAWZONE: MAPPING UNMET LEGAL NEED
}

\section{Richard Owen, Swansea University, UK}

Abstract: Mapping unmet legal need assists university law clinics plan activities to meet the needs of the communities they serve. This article, by looking at a project where students started mapping unmet legal need in their locality, will consider the pedagogical issues associated with identifying unmet legal need and how it might enable university law clinics to be better embedded into their local communities by considering aspects of physical and human geography when considering injustice. It will also look at exiting research methodologies in this area and how mapping unmet legal need can develop students' empirical research skills. The article also assesses the project's aims to develop attributes such as entrepreneurship, as well utilising teaching practices such as visualisation to enable students to think spatially to perceive and understand social inequalities more clearly. It will argue that involving students in mapping unmet legal need will help them make those services more accessible; devise holistic solutions to clients' problems; and enable them to work more effectively with other disciplines to both their own and their clients' benefit.

There is a strong tradition within clinical legal education of advocating that clinics be embedded in their local communities. There are a number of related theories which reflect this idea such as rebellious lawyering: empowering clients through grassroots, community based advocacy in low income communities, facilitated by lawyers, to bring about meaningful social change; and client-centred lawyering: the idea that clients should be the primary decision-maker in determining the direction of their legal case or transaction, whereas their advisers should maintain the appearance of neutrality and be as 
objective as possible. Both theories are united in their belief that the lawyer, and by extension the law clinic, must be strongly embedded in their local communities and serving their legal needs.

But what are those needs, when can they be defined as legal needs, and why is this of interest? If there is unmet legal need that should be of concern to us as citizens, as it undermines the rule of law; it should be of concern to the legal profession as it shows their services are inaccessible to a section of the public; and it should be of concern to policymakers as it reveals that a section of the public are unable to access the advice they need in order to allow policies to achieve their objectives. There is no one who wants to visit a law firm for its own sake. Clients instruct lawyers because they are viewed as the agents who can arrange their divorce, recover their debts, obtain their welfare benefits, etc. In other words, the demand for lawyers does not exist independently of the ends the client is seeking to achieve.

There is some evidence of failure on the part of the legal profession in England and Wales to identify and address their clients' needs. Some groups seem to prefer to avoid lawyers if they possibly can. A survey of small businesses in England and Wales found that almost 50\% would use a lawyer only as a last resort and only $13 \%$ found them to be cost effective. ${ }^{1}$ Representatives of small

1 Robert Blackburn, John Kitching and George Saridakis, 'The legal needs of small businesses: An analysis of small businesses' experience of legal problems, capacity and attitudes' (Kingston University for the Legal Services Board, 2015). 
businesses have also talked of a 'considerable failure' by lawyers to meet their needs. ${ }^{2}$

Although there is a large body of literature on legal need there have been methodological problems in defining what is meant by the term. The early literature from the 1930s to 1970s presented survey respondents with problems to which there were potential legal solutions. If respondents had experienced the problem but had not received the assistance of a lawyer in resolving it then the problem was classed as an unmet legal need. ${ }^{3}$

The drawback with this approach is that it privileges legal solutions over all other possible outcomes. Clients might want to rationally avoid legal solutions to their problems. For example, if your line manager is harassing you at work you may take the conscious decision to avoid the problem and move to another job thereby avoiding the risk, the stigma, stress, and uncertainty of taking the case to an Employment Tribunal. Avoiding the issue as a legal problem could be the most rational, advantageous solution for that particular client. Whereas another client, faced with similar facts but lacking the same mobility, will have no choice but to face up to it as a legal problem.

2 John Hyde, 'Small businesses say lawyers failing to meet their needs' The Law Society Gazette (London 30 March 2016) <http://www.lawgazette.co.uk/news/smallbusinesses-say-lawyers-failing-to-meet-their-needs/5054452.fullarticle $>$ accessed 2 August 2016

3 Pascoe Pleasence and others, 'Local Legal Need' (Research Paper 7 Legal Services Research Centre, January 2001, London). 
Since the 1970s the methodology has become more sophisticated and focuses more on the ends that the client wishes to achieve. In order to prevent privileging legal solutions over other types of resolution the focus is now on problems where a legal solution is just one out of a number of possible outcomes with greater emphasis on what the client wants. ${ }^{4}$

Mapping a community can assist in the process of identifying unmet legal need as particular groups are likely to encounter legal problems of a particular type. ${ }^{5}$ The more socio-economic data that is available about the community the clinic serves the better the clinic can prepare to meet the needs of that community, as data of a very large size, which is often referred to as Big Data, can help predict the problems they are likely to face. Not only are particular groups likely to face particular problems but also they are likely to face clusters of problems so Big Data is also likely to predict their correlation and interrelationship, as well. ${ }^{6}$ Big Data and its increased availability facilitates greater predictive modelling of a law clinic's needs. The availability of small area data means there is an abundance of data at the level of local council ward, which further increases the opportunities to target their services efficiently and effectively in an evidence-based way. However, there are limits to Big Data's efficacy.

\footnotetext{
$4 \quad$ Hazel Genn, Paths to Justice: What People Do and Think About Going To Law (Hart Publishing 1999). See also Pleasance and others (n 3) paras. 7 - 8.

5 Pascoe Pleasance and others, 'Multiple Justiciable Problems: Common Clusters and Their Social and Demographic Indicators' [2004] 1(2) Journal of Empirical Legal Studies 301

$6 \quad$ Pleasance and others (2004) (n 5)
} 
Predictors can vary between geographical locations. ${ }^{7}$ Some locations may simply buck the trend whilst it is possible to have 'postcode deprivation': a tiny pocket of deprivation surrounded by relatively more affluent neighbourhoods. ${ }^{8}$ Variation in the prevalence of legal problems between different areas has also been found in other common law jurisdictions. ${ }^{9}$

Law clinics, therefore, need to balance the predictable whilst being simultaneously sensitive to the possibility of the statistically unpredictable in their communities. They can achieve this by being not just closely involved in but part of their local communities in ways that have been advocated by the rebellious lawyering school. This close engagement heightens their awareness of those myriad contextual issues, such as crime rates, affecting their communities which may or may not mean that they deviate from the statistical norm or come to realise that there are micro pockets of relative deprivation in otherwise more relatively affluent areas.

In this article, I will examine a project which started in the Essex Law Clinic, which is part of the University of Essex, in the 2014-15 academic year called LawZone Colchester. This is a long-term project that seeks to map unmet legal need in the town and eventually, it is planned, be rolled out to map unmet legal need throughout the county of Essex in the east of England.

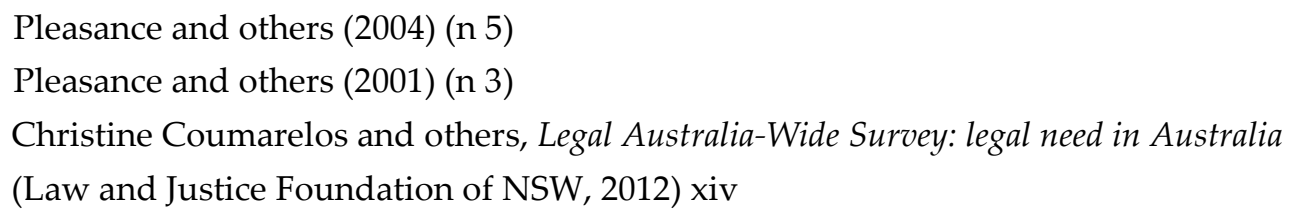


The Essex Law Clinic was established in 2008, but in 2014 a decision was taken to expand its activities. One member of staff was recruited to be dedicated to clinical activities. He was supported by the Students' Union Advice Centre who administered the Clinic, amongst other things, they took initial inquiries from potential clients and assessed whether they would be suitable cases for the Clinic's students and managed files. The Clinic had a few projects, but LawZone was intended to support the project that involved face to face interviews with clients. This project involved an initial forty-five-minute information gathering interview with clients followed by an advice letter providing initial advice and assistance to them. The interview and advice letters were either supervised by the Law Clinic Director or a member of the local legal profession. Starting in the 2014/15 academic year a maximum of twenty students could engage in this type of clinical activity on an assessed basis although more students could be assessed on other clinic activities. There were also opportunities for approximately thirty more students to be involved on an extracurricular basis for this clinical activity. Again, more students were involved on an extracurricular basis for other clinical activities.

It was decided that the student advisors should be involved in the Clinic's expansion as much as possible. One of the reasons behind this was to give students experience of all facets of the Clinic's activities such as strategic and business planning. The greater the degree of student autonomy over the 
expansion plans the more authentic it became as an exercise in strategic and business planning.

The desire to introduce this type of planning was motivated by several factors. Firstly, to raise students' awareness of the need to work in an interdisciplinary way to best meet the complex and multifaceted needs of clients. Legal needs are often connected to non-legal needs, for example poor mental or physical health can lead to consumer issues if earning capacity is affected as only cheaper goods and services can be afforded, so an awareness of how other disciplines work will enhance students' effectiveness as clinicians. Secondly, there is evidence that legal students need to acquire business skills to enhance their employability. The Solicitors' Disciplinary Tribunal has claimed that some solicitors 'do not have the rounded set of skills to run a business'. ${ }^{10}$ The leaders of the largest UK law firms say the skills future lawyers need will increasingly include business skills such as project management and financial acumen. ${ }^{11}$ Thirdly, part of the liberalisation of legal services in the UK brought about by the Legal Services Act 2007 has been the creation of alternative business structures (ABSs). This allows non-lawyers to manage or have

$10 \quad$ Neil Rose 'Number of solicitors appearing before SDT on the up amid warning over poor business skills' Legal Futures (10 June 2016) <http://www.legalfutures.co.uk/latestnews/number-solicitors-appearing-sdt-amid-warning-poor-business-skills $>$ accessed 4 August 2016

11 Grania Langdon-Down, 'Well-targeted training will give solicitors the skills to succeed' The Law Society Gazette (London 4 November 2010) < http://www.lawgazette.co.uk/analysis/well-targeted-training-will-give-solicitors-theskills-to-succeed/57894.fullarticle> accessed 4 August 2016 
ownership-type interest in legal firms. The only restriction on the services an ABS can provide is that it must not engage in any activity which conflicts with a lawyer's role. Greater business acumen will allow law graduates to compete more successfully in such an environment.

It also seemed right in principle to involve students in the Clinic's development to ensure that it was meeting their career needs and aspirations. The students were an important resource in the Clinic's development bringing perspectives and skills that would otherwise be lacking.

There were significant cuts to civil legal aid in the United Kingdom in April 2013 as a result of the Legal Aid, Sentencing and Punishment of Offenders Act 2012 (LASPO) in both the scope of assistance and the level of funding. Divorce, child contact, welfare benefits, employment, clinical negligence, and housing law cases are now outside the scope of civil legal aid unless there are exceptional circumstances.

This has created fresh challenges for access to justice and created greater pressure for innovation in the delivery of legal services, particularly in the fields of social welfare and family law. The Lord Chief Justice of England and Wales, Lord Thomas of Cwmgiedd, has said that: 'There is a vital need for young people to be involved in reshaping the civil justice system in light of the cuts to civil legal aid in April 2013.' ${ }^{12}$

12 The Right Hon. The Lord Thomas of Cwmgiedd, 'Reshaping Justice' (Lecture delivered to Justice on $3^{\text {rd }}$ March 2014 at para. 21.) 
Lord Thomas seems to suggest that young people, as digital natives, will respond to the challenges of providing access to justice in fresh ways which will be innovative in the use of information technology.

It is not just the affordability of legal services that restricts access to justice. There are other factors at play such as geographical access. Currently there is an extensive court closure programme currently being undertaken in England and Wales, which means that, in some areas, people will not be geographically proximate to a court. ${ }^{13}$ Again, an ability to innovate in the use of information technology will be a particularly useful skill in meeting this challenge, as well. Typically, surveys of unmet legal need have been large-scale. ${ }^{14}$ However, a number have reported on the possibility of small-scale local variations. This article will aim to put the literature into the context by looking at the communities the Essex Law Clinic serves, particularly the Greenstead and

$<\underline{\text { https://www.judiciary.gov.uk/wp-content/uploads/ICO/Documents/Speeches/lcj- }}$ speech-reshaping-justice.pdf $>$ accessed on 22nd October 2015

13 Ministry of Justice and HM Courts and Tribunals Service, 'Response to the proposal on the provision of court and tribunal estate in England and Wales' Response published on 11 February $2016<$

https://www.gov.uk/government/uploads/system/uploads/attachment_data/file/4995 18/national-consultation-document.pdf> accessed 4 August 2016

14 There have been at least 26 large-scale surveys of the public's experience in the last twenty years in at least fifteen jurisdictions: Pascoe Pleasence, Nigel Balmer and Rebecca Sandefur, Paths to Justice: A Past, Present and Future Roadmap Report prepared under a grant from the Nuffield Foundation (UCL Centre for Empirical Legal Studies, August 2013), 3 
Hythe areas of Colchester where many students live, as well as the pedagogical issues involved in clinic students assessing unmet legal needs.

In terms of the methodology used, a group of eight undergraduate students in the 2013/14 academic year initially identified all legal advice providers within the boundaries of Colchester Borough Council by pinning them on a map. The pins were colour coded way to denote whether the provider was a legal firm, on the one hand, or a not for profit provider, on the other.

This was a start but more significant progress was made in succeeding academic years. Mapping unmet legal need, and methodologies for approaching the topic, was included as part of the induction programme for the twenty undergraduate students who were assessed for this type of clinical activity, and classroom discussions reflected on approaches to this issue.

In the 2015/16 academic year one student adviser digitised this map, and added other locations which he felt were of actual or potential importance to the Clinic's clients. Future generations of students can make further additions to this digital map as further work is undertaken, so it is a living document.

A review of files since the Clinic's inception in 2008 was undertaken recording the subject matter of each inquiry. All the files relating to face to face interviews were recorded: the Clinic runs a number of other projects on prison law, miscarriage of justice and various contract research projects but these were not included in the review. The reason for their exclusion was that clients from these other projects are not drawn from the local area, and one of the reasons 
behind embarking on the project was to become more knowledgeable about the legal needs of the local vicinity. A student adviser initially evaluated the data before the author undertook a further evaluation.

In order to provide guidance to students embarking on research into unmet legal need there had to be some definition of what was meant by the term. The definition that has been used is to identify whether there is any statistical or other evidence which suggests that people in the community are unable, or are encountering obstacles, in accessing advisory services to assist with problems where a legal solution may be one possible option in its resolution.

In Part One the possible pedagogical benefits of mapping legal need in a clinical legal environment is examined. In Part Two the project itself is evaluated. In Part Three the issues surrounding the educational management of a long-term project where different cohorts of students will work on the project over time is considered.

Part One: Pedagogical Benefits of Mapping Legal Need in a Clinical

\section{Environment}

There are good pedagogical reasons for teaching clinical students about legal need in their communities. At the most fundamental level it partially fulfils the regulatory requirements for law degrees in the United Kingdom. The Quality Assurance Agency for Higher Education (QAA) is the independent body entrusted with monitoring and advising on standards and quality in UK higher 
education. Its UK Quality Code for Higher Education aims to give all higher education providers a shared starting point for setting, describing and assuring the academic standards of their awards and programmes. The Subject Benchmark: Law is the QAA document which defines what can be expected of a graduate on a legal studies programme, in terms of what they might know, do and understand at the end of their studies. ${ }^{15}$ Paragraph 2.4 (vii) of the Benchmark Statement provides that law graduates must 'demonstrate ability to work with a range of data, including textual, numerical and statistical'. Mapping legal need meets all aspects of paragraph 2.4 as it requires the need to be aware of how the wider societal context affects qualitative interpretation of data; the need to process Big Data together with an appreciation of its limits in terms of predicting legal need; and a need to understand how numerical information generated by clinic users relates to other numerical and statistical information.

Legal process individualises problems. Providing students with an overview of recurring problems in the clinic gives them a framework to consider issues of justice and lawyering. It incorporates a socio-legal dimension into their clinical legal education; it develops their quantitative and qualitative research skills as they need to be able not only to process Big Data but also interpret statistical evidence particularly by examining whether there are inherent biases

15 Quality Assurance Agency (QAA), Subject Benchmark Statement Law (QAA, July 2015) 
in the collection of data; it develops their entrepreneurial skills as they seek to devise innovative methods to their community's challenges; and it will make them think of the need to work in an interdisciplinary way in order to devise solutions to the complex, multifaceted and interconnected problems that communities face.

There can be other socio-legal dimensions. It is an opportunity to reconceptualise the law and legal proceedings with students being encouraged to think about clients' wellbeing more generally, as well as seeing issues more clearly from a client's and potential client's perspective. A legal intervention can be seen as possible evidence that an opportunity to address wellbeing has been missed in the past. Students can be taught to see the need for intervention of legal process as a type of failure. They can rewind the client's problem and return to its origin. Can they then identify any form of earlier intervention that would have prevented the problem developing to the point where the stress, expense, delay, and risk of legal proceedings could have been avoided? To answer this question they will need to think holistically and draw on the experiences of neighbouring disciplines.

It also develops attributes not normally associated with legal education. For example, it develops their spatial thinking, and to think in a multi-dimensional way when it comes to space. Spatial thinking has been defined as consisting of three elements: 'concepts of space, tools of representation, and processes of 
reasoning. "16 Although spatial thinking is a skill which pervades all disciplines, it develops in the context of specific disciplines and it 'becomes transformed and refined through training and extensive practice. ${ }^{17}$ A person is spatially literate when they 'can match the norms for what should be known about space, representation, and reasoning. ${ }^{18}$

Spatial thinking, therefore, is a vital skill when it comes to mapping unmet legal need. It will assist students in identifying areas which buck the trend or 'postcode deprivation' when clinic data does not match legal need based on predictive modelling. They also need to think as to what space it is that their community occupies. There can be variable geometry when it comes to defining the catchment area of a clinic. Are the boundaries drawn according to neighbouring streets, council ward, city limits, interest group, subject matter, cyberspace or by other criteria to be defined by the students themselves?

It is not just physical space which can be spatialised. Are there needs of groups which could be defined by sex, race, religion, age, disability, social class, sexual orientation, nationality that the clinic is failing to meet? Whilst the initial manifestation of these groups will be non-spatial in nature, thinking about

16 Committee on the Support for the Thinking Spatially, Committee on Geography, National Research Council Learning to Think Spatially: GIS as a Support System in the K-

12 Curriculum. (National Academies Press, 2005) ix

$17 \quad \mathrm{~N} 16,5$

$18 \quad \mathrm{~N} 16,18$ 
them spatially can bring new reasoning processes to bear, which will assist in the resolution of problems. ${ }^{19}$

A study of local unmet legal need will not only develop students' intellectual skills but also their professional skills. It is a particularly suitable vehicle to explore issues surrounding client care, and how advising involves a partnership between lawyer and client. In seeking to identify unmet legal need it is necessary to develop the service with the active involvement of the client and the community. This illustrates to students that the service is not something that is done to the client, but should be a product of a partnership: the outcome of research into the client base and discussions between clients and community groups.

It should give insight into business planning. Technological innovation has been recognised as creating the potential for realising 'latent demand'. ${ }^{20}$ Digitising patterns of demand for legal services will create a database which will help identify gaps in the market where inhabitants may not have traditionally found legal services to be accessible.

Becoming knowledgeable about the client base and their socio-economic characteristics can also assist business planning as to a certain extent it can assist in the prediction of clients' needs. Whilst the limits of the ability to do

\footnotetext{
$19 \quad \mathrm{~N} 16,31$

20 Richard Susskind and Daniel Susskind, The Future of the Professions: How Technology Will Transform the Work of Human Experts (Oxford University Press, 2015) 133 - 134
} 
this are discussed above, it is still the best starting point for planning the clinic's future activities. If it can be seen that a particular problem is bedevilling a community that might condition the clinic's activities, as it offers the opportunity of targeting resources and strategising more effectively. For example, the clinic may decide to alter its activities and instead of giving individual assistance in a certain subject area it might decide it will have greater impact with more efficient use of resources if it focuses on public legal education instead.

To assess legal needs effectively requires a study of all facets of a community to gain greater insight into the causes of problems which face that community, and to imagine solutions to them. This includes assessing its social capital: the links, shared values and understandings in society that enable individuals and groups to trust each other and so work together, ${ }^{21}$ and gauging the community's resilience: utilising available resources to withstand, respond to and recover from adversity. ${ }^{22}$ Potential partners need to be identified who may assist in the resolution, or even the prevention, of these problems.

The identification of potential partners is a welcome broadening of law students' education. It demonstrates that law is not the only tool in the toolbox. It also gives them experience of working with people from other disciplines.

21 OECD Insights: Human Capital, 'What is Social Capital?' < http://www.oecd.org/insights/37966934.pdf $>$ (accessed on 24 $4^{\text {th }}$ April 2017)

22 RAND Corporation, 'Community Resilience' < http://www.rand.org/topics/community-resilience.html $>$ (accessed on 24 th April 2017) 
Interdisciplinary working is not only right in principle because of its holistic approach; it also enhances the students' employability. Scholars who have investigated the future for legal services have identified the need for them to diversify and become increasingly multidisciplinary. ${ }^{23}$ This will require meaningful engagement with neighbouring disciplines such as management science and business studies, but other areas too such as geography. ${ }^{24}$

In the United Kingdom the need for lawyers to work increasingly with other professions, such as accountants and management consultants, has been facilitated by regulatory change as a result of the introduction of ABSs. Working with other groups will give students experience of working with nonlawyers providing insight into their working methods which is a transferable skill of increasing importance in the legal workplace.

\section{Part Two: Mapping LawZone}

In this section, the issues arising from the experience of running a long-term project currently called LawZone Colchester but eventually, it is planned, evolving into LawZone Essex will be assessed. The historic town of Colchester, which is the United Kingdom's oldest recorded town, has a two-tier local

\footnotetext{
23 Richard Susskind, Tomorrow's Lawyers: An Introduction To Your Future (Oxford University Press, 2013) 113

$24 \quad \mathrm{~N} 23$
} 
authority structure and falls within the boundaries of Colchester Borough Council and Essex County Council.

Initially, the project was thought necessary because this part of the county of Essex has a weak legal identity. The local law society is the Suffolk and North Essex Law Society so its boundaries are not coterminous with either the borough or county boundaries with its remit reaching into the neighbouring county of Suffolk.

The institutional structure does not exist, therefore, to consider issues, which might affect the county uniquely or with a particular intensity. It was thought that a project of this nature had the potential to influence policy making at the borough and county level through the accumulation of anonymised socioeconomic data from clinic clients and the mapping of unmet legal need. Whilst there have been a number of large-scale surveys which have increased understanding of unmet legal need, it is recognised that there are gaps in the evidence base. ${ }^{25}$

This project is an opportunity to give students experience of measuring impact in quantifiable and qualitative ways. Legal needs surveys have been shown to have impact and their use and impact has varied as a response to regulatory, economic and political change. There is evidence that they have influenced legal aid policy in the United Kingdom. ${ }^{26}$ However, since the civil legal aid cuts

$\begin{array}{ll}{ }_{25} & \mathrm{~N} 14,51 \\ 26 & \mathrm{~N} \mathrm{14}, 42\end{array}$


of April 2013, and the liberalisation of legal services, they have also had an impact on understanding of public justice, as well as private and not for profit market service provision. ${ }^{27}$

When commencing a project of this sort the students can be given a large degree of latitude as to what they explore because there is so much data that could be mined which will potentially be useful. There is a balance to be struck between students needing support and guidance, on the one hand, and allowing the space they need to imagine the future of justice and legal services in relation to their clinic, on the other, if Lord Thomas's vision of young people shaping the civil justice system is to be realised, and we are to receive the benefits of their fresh perspectives as a result of their digital nativity.

The project started low tech with a group of students pinning the location of legal advisers in the town of Colchester on a paper map with different colours being used depending on whether or not it was a legal firm or a free advice provider. This map was then digitised. The exercise was then extended into the mapping of social infrastructure of the town. Various additions were made to it such as an emergency night shelter and railway stations. The more this is mapped the easier it will be to assess the town's resilience.

The inclusion of railway stations produced an interesting result. Colchester is approximately fifty minutes by express train from London Liverpool Street

$27 \quad$ N 14, 44 
station, which is in the heart of the City of London (the financial district of the capital) where there are a great number of well-paid jobs in financial services. Hythe station is the closest to the university, and therefore Essex Law Clinic, and is in a relatively deprived socio-economic area compared to Wivenhoe station, which is the next closest to the university and is in a more prosperous area.

The students had mapped the stations as part of the mapping of the social infrastructure of the Clinic's catchment area to help assess the community's amenities. However, the author could point out to the students that this is possibly an example of inequality being designed into the environment as there are a greater number of direct trains to London Liverpool Street from Wivenhoe than from Hythe. This is also hard to understand as the two stations are on the same railway line.

Easier access to London Liverpool Street means easier access to the high paying jobs in financial services. Hythe residents will have their journey time increased by often having to change trains with on costs, such as extra child minding fees, often arising from this. In this way, it was possible to model to the students what was required.

The difference in the train service meant it was possible to consider whether there was a 'power geometry' i.e. 'relations to [the] flow and interconnections' 
between different social groups and different individuals. ${ }^{28}$ Why should Wivenhoe have so many more direct trains to London than Hythe when the two stations are on the same railway line? Is it because the people Wivenhoe are better organised? Or is it because of some other reason?

This example was also used to communicate the concept of social capital/infrastructure and how concepts such as spatial injustice may apply to their findings. It could be used to argue that inequality can be geographically constructed. The review of files since the Clinic's inception found the following:

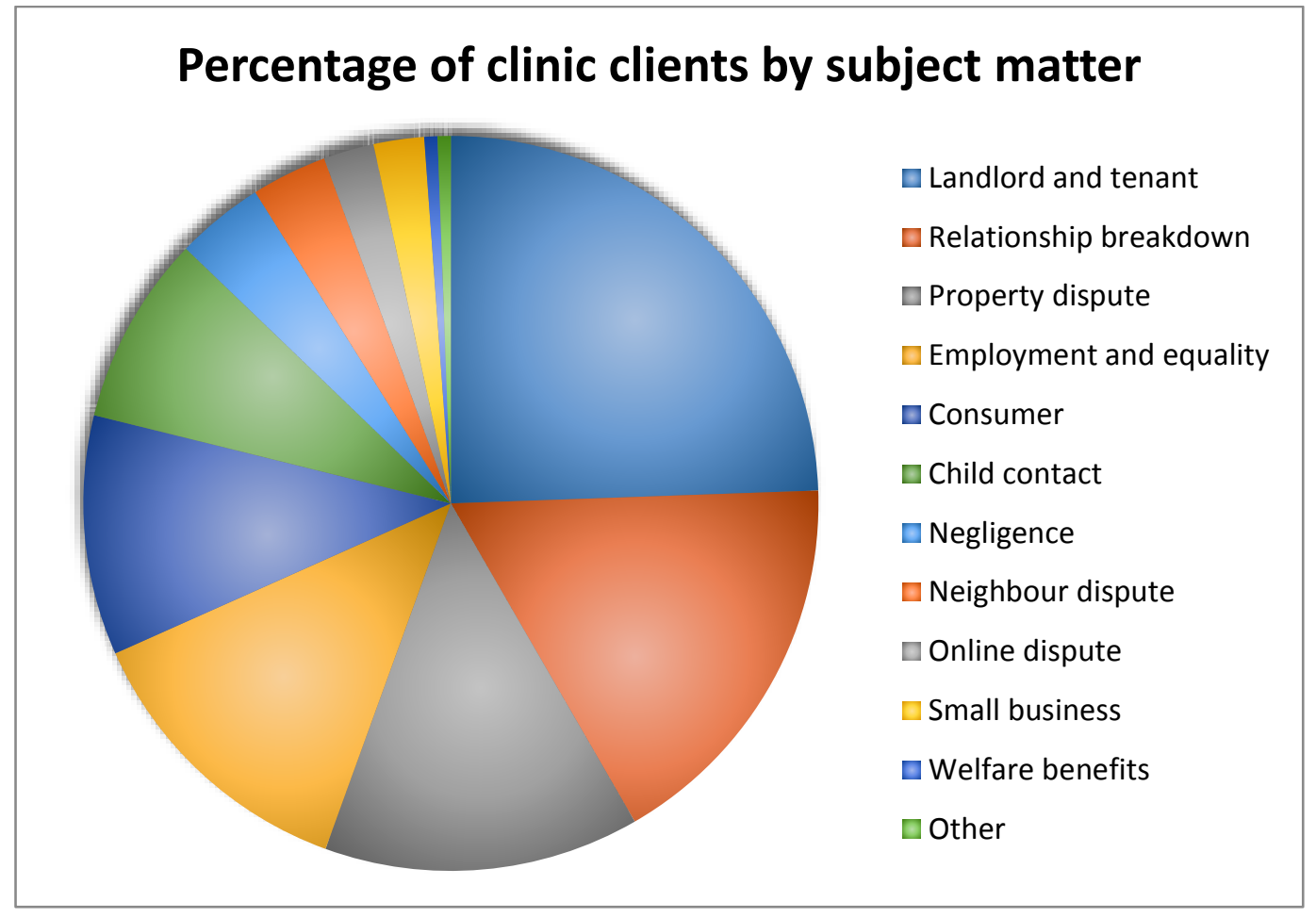

Table One: Percentage of Essex Law Clinic clients by subject matter since 2008 
The percentage of landlord and tenant disputes (24.44\%) is not surprising. A high percentage of the Clinic's clients are students who frequently live in rented property and therefore more likely to encounter problems with landlords. If you also consider problems students also encounter from time to time with letting agents, which came within the category of property disputes, and were $13.88 \%$ of the Clinic's casework, then it can be seen that a total of $38.32 \%$ of cases were meeting the legal needs of predominantly students and some University staff.

Whilst landlord and tenant cases make up a significant portion of the Clinic's caseload it is likely that the Clinic is not meeting the legal needs of a substantial part of the population it serves. Most housing cases are referred to the Clinic by the University's Students' Union and therefore the students are clients.

The Law Society of England and Wales have produced an interactive map which found a lack of State funded housing advice in England and Wales as a result of the civil legal aid cuts in April 2013. ${ }^{29}$

29 The Law Society, 'Legal Aid Deserts Campaign' (Briefing for Local Law Societies) August 2016 


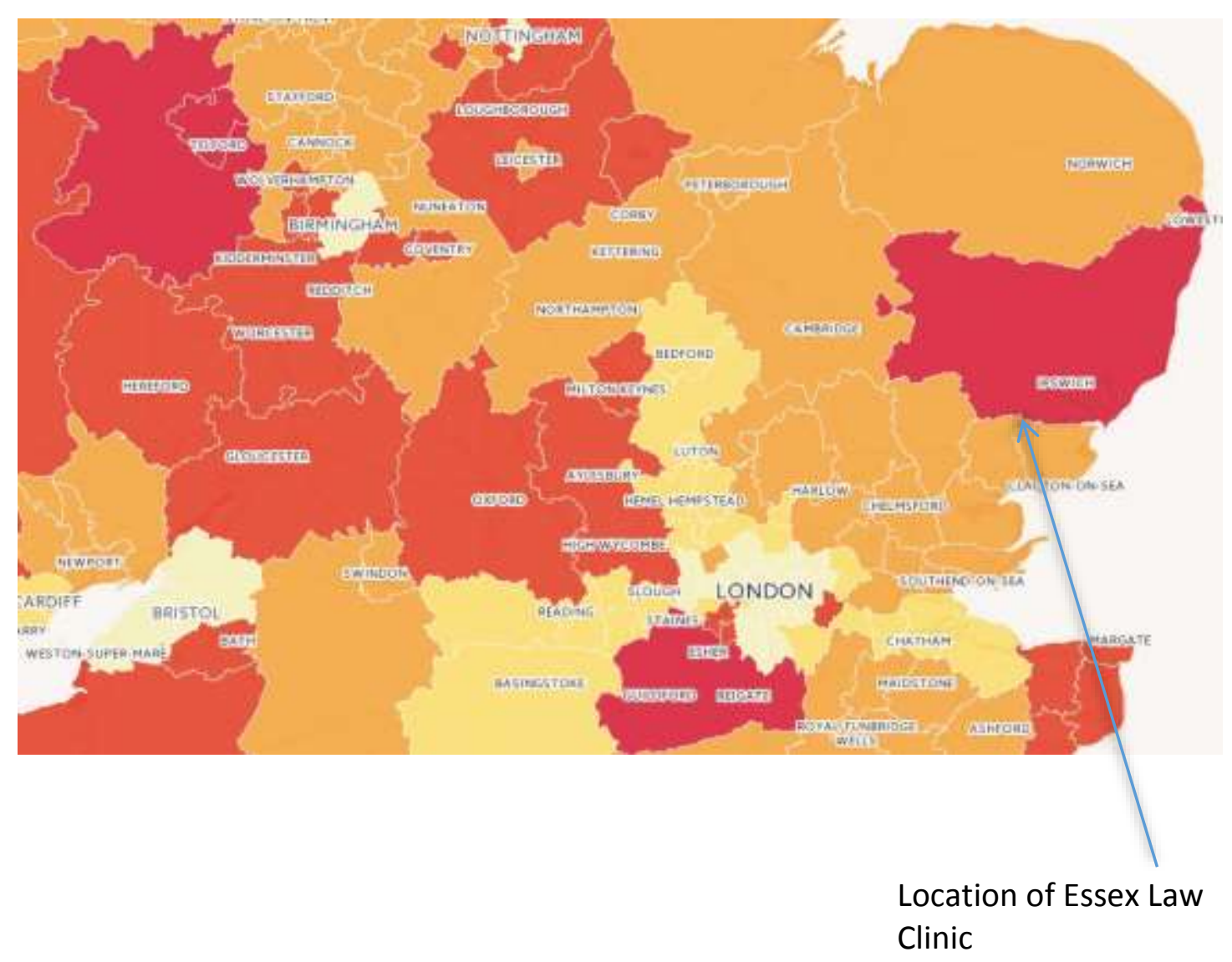

Figure one: The Law Society's Interactive Map showing the county of Suffolk as a legal aid housing advice red spot where no State funded legal advice is available

The map was useful in getting students to visualise the varied and scarce distribution of legally aided housing advice. The legal aid area to the immediate north of the Clinic, Suffolk, was a red spot with no legal aided housing advice available. Colchester is marginally better served as the charity, Shelter, provides free housing advice in the town; however, Shelter has had its own funding also cut which affects the volume of cases it can serve. This 
strongly suggests that there is demand in the wider community for free housing advice which the Clinic is currently not able to meet.

It is just possible that all we were seeing was the clinic staff and student advisers' cosmology, i.e. how they make sense of the world based on their physical, social, spiritual and mental world, and failing to see a wider cosmology in respect of housing need in the Clinic's own local community. In this cosmology the Greenstead and Hythe areas of Colchester had housing advice needs dominated by their undoubtedly large student population. However, 'the cosmology of "only one narrative" obliterates the multiplicities, the contemporaneous heterogeneities of space'.$^{30}$ Within Greenstead and Hythe there would be those

with different cosmologies, and who would not imagine the place as being dominated by the University with the need to service its students' housing needs. They may not even give the University much thought at all. They will have their own cosmologies, which do not involve working or studying at the University, but involve an altogether separate existence. This is the 'contemporaneous heterogeneities' Massey is referring to.

The danger in just seeing the headline figure of $24.44 \%$ of the Clinic's caseload being landlord and tenant cases is that it can give a misleading impression as 
to how well or otherwise the Clinic is meeting the local community's housing advice needs.

It would seem that the Clinic is doing well in meeting these needs in an area where housing advice is sorely needed. However, when the data is further examined then it can be seen that most of the clients in landlord and tenant cases had some connection with the University whether as students or, occasionally, staff. They were more likely to be aware of the Clinic and its services through their proximity to it on campus, but 'contemporaneous heterogeneities' within Greenstead and Hythe may mean that there are other communities co-located within the same locality who are not getting their housing advice needs met.

The problems the Clinic was encountering tended to be with issues such as representations made prior to letting properties, return of deposits, and properties in multiple occupation. These are problems that could be predicted from a client base involving largely students. It could be that clients with a different background might have other problems such as serious repairs, etc. The importance of this is to ensure that the data collected from clients can distinguish between the University's students and staff, on the one hand, and members of the general public not connected to the University, on the other. Only then will it be possible to assess if the Clinic is addressing the needs of all parts of the locality, which will prevent 'only one narrative' dominating thinking. This was a good topic from a pedagogic perspective as it was 
possible to flip the normal question. Instead of asking what effect the students have or could have on the community the question was reversed and the students were asked what effect they might be having on the community.

The next most numerically significant area is in relationship breakdown, which comprised $17.22 \%$ of all cases; however, if child contact cases are also included which are $8.33 \%$ of all cases this makes a total of $25.55 \%$. The scope of legal aid funding in the United Kingdom for relationship breakdown has been significantly reduced in scope since the cuts to civil legal aid spending were introduced in April 2013. This will explain the increase in the most recent periods of the Clinic's operation.

The increase in the volume of relationship breakdown cases is strongly suggestive of unmet legal need. The Essex Law Clinic only provides initial advice and assistance in such cases. Clients are frequently looking for on-going legal support which the Clinic is unable to provide beyond signposting further avenues of advice and assistance.

The effect that the civil legal aid cuts had on the levels of relationship breakdown cases coming to the Clinic illustrates the need not only to map the Clinic's activities by place, but to map temporally as well. This has been done by colour coding, by year, types of inquiries onto the map although in housing cases this has been done seasonally to reflect periods when undergraduate students are on vacation. 
Mapping temporally showed a different pattern of advice needs before the legal aid cuts. They increased demand for relationship breakdown advice, but is this a spike or has demand in this area reached a new plateau? The immediate period after the cuts could have produced a shock which causes a spike in demand, but then as technological innovations, new business models, new advice providers enter the market the situation may ease and could change over time. It will only be possible to assess this if demand is mapped temporally in addition to mapping by place.

There has only been a slight increase in employment and equality cases in recent years, but this is probably evidence of unmet legal need of a different sort. Fees were introduced for bringing cases to Employment Tribunals for the first time in July 2013 except for those who could claim a waiver or reduced fee on the grounds of limited wealth or low income.

The introduction of Employment Tribunal fees saw a sharp decrease in the number of claims being taken to a tribunal in the first year with the Ministry of Justice recording a $70 \%$ reduction. ${ }^{31}$ The fees were introduced as part of a change in policy whereby the government argued that the users of the tribunal system should pay, and it came after employers' organisations had long argued that there should be some restriction on the bringing of weak or vexatious

\footnotetext{
31 Ministry of Justice, Tribunal Statistics Quarterly April - June 2014 (11 September 2014), 7 $<$ https://www.gov.uk/government/uploads/system/uploads/attachment_data/file/3529 14/tribunal-statistics-quarterly-april-june-2014.pdf> accessed 15 August 2016
} 
claims. The fact that the demand for employment and equality advice has risen, despite such a decrease in claims being made, suggests that clients are still encountering problems in their relationship with their employers but now find it hard to access systems of redress.

Recording the number of employment and equality cases provided further evidence that mapping unmet legal need has to be a collaborative effort between tutor and students. Between 2008 and 2016 the Clinic did not receive a single inquiry for advice on an equality issue from the LGBT+ community as a result of clients attending face-to-face interviews. However, the Clinic is involved in another project advising on prison law with the Prisoners' Advice Service where $10 \%$ of all inquiries are requests for advice on aspects of equality law from the LGBT+ community, which statistically seems more in line with what could be predicted given the size of the LGBT+ community as a proportion of the general population.

This does raise issues about unmet legal need and the LGBT+ community. It could be argued that it is evidence that their needs are well met, and they have no need to access university law clinics. Stonewall is an organisation which lobbies and campaigns on issues of relevance to the LGBT+ community. They operate a telephone information helpline and will also give advice via email. Assistance can also be accessed from the Equality Advisory Support Service (EASS) discrimination helpline. The service provides advice on discrimination 
in employment and services and although it is possible to contact the service directly, they prefer referrals from advisory organisations.

Assistance is also available from the Equality and Human Rights Commission's website, and the normal channels for those looking for equality advice such as Citizens Advice Bureaux, Law Centres, the Free Representation Unit (for those on low income), etc.

Whilst it is possible that members of the LGBT+ community have a preference for using a service dedicated to their needs this is only provided nationally by Stonewall. The other services such as the EASS and the Equality and Human Rights Commission are services that deal with discrimination in relation to all protected characteristics under the Equality Act 2010, and the rest are general advisory services.

Despite the excellent work all these services do it seems unlikely that they will completely meet the legal needs of potential LGBT+ clients for the Essex Law Clinic. It may be that the Clinic is not perceived as being sufficiently welcoming to this particular community. Queen Mary, University of London has established a dedicated clinic, Pink Law, which through its marketing makes a public commitment to offer a welcoming and confidential environment to the LGBT+ community..$^{32}$ Previous studies of unmet legal need have concluded that a number of strategies are required to combat it including

32 Queen Mary University of London, 'Pink Law'

<http://www.lac.qmul.ac.uk/advice/pink/index.html> accessed 16 August 2016 
tailoring services for specific problems and for specific demographic groups. ${ }^{33}$ It might be that the Essex Law Clinic, and other university law clinics, will not respond to the legal needs of this community unless they clearly identify themselves as catering for the community's needs, which means that the marketing and presentation of clinics should be an integral part of students' legal education.

Negligence cases, mainly personal injury cases, constitute $3.88 \%$ of the Clinic's caseload, which is small. Litigation is a reserved activity in England and Wales so only members of the legal profession can undertake it, and it is not permissible for student advisers to do so. Therefore, the Clinic only gives preliminary advice in such cases.

The $3.33 \%$ of cases of the Clinic's caseload that relate to neighbourhood disputes seems low on a statistical modelling basis, i.e. the numbers of that type of case that could be expected using crime rates as a proxy for legal need. Many of the Clinic's clients come from the Greenstead area of the St Andrew's council ward. This is an area of relative social deprivation. High levels of deprivation are a predictor of civil justice problems with, on a statistical modelling basis, $25 \%$ greater chance of neighbourhood disputes. ${ }^{34}$ The Clinic's clients do not all come from this area and many come from more economically affluent areas; it

\footnotetext{
$33 \quad \mathrm{~N} 9, \mathrm{xxi}$

$34 \quad$ Vicky Kemp and others, 'The Problems of Everyday Life: Crime and the Civil and Social Justice Survey' (Briefing 5) [2007] Centre for Crime and Justice Studies, 3
} 
is also possible that there is a local variation and the area does not accord with statistical modelling patterns.

However, this seems unlikely. Data is collected on a council ward basis. Looking at the accompanying map, if the Harwich Road is seen a boundary and the area north east and north of Greenstead but within the St Andrew's ward is excluded and the Hythe area, i.e. that area to the south east of Greenstead bound by the river and roads, is included then the crime rate is higher than that suggested by the figures at ward level indicate, which makes the caseload for neighbourhood disputes seem even lower than it should be on a predictive statistical basis.

The area of Greenstead and the part of Hythe bound by the river could be a 'social space', i.e. a space which is different from the physical space which planners normally use. ${ }^{35}$ 'Social space' has to incorporate both the geographical and sociological imaginations and is an area with a 'different attractive power' ${ }^{36}$ Mapping unmet legal need can therefore lead to a form of variable geometry: redefining boundaries of communities according to their 'attractive power'. Redefining the boundary of the St Andrews ward not only brings the challenges that area faces into sharper focus but also offers the

\footnotetext{
35 David Harvey, Social Justice and the City (Revised Edition, University of Georgia Press, 2009), 35

$36 \quad \mathrm{~N} 35$
} 
opportunity of embedding student advisers more deeply into the community as it is an area with a high density of student population.

This form of spatial analysis requires an interdisciplinary set of skills on the part of the students. They need the space-time analytical skills of a geographer and the personality trait analytical skills of the sociologist.

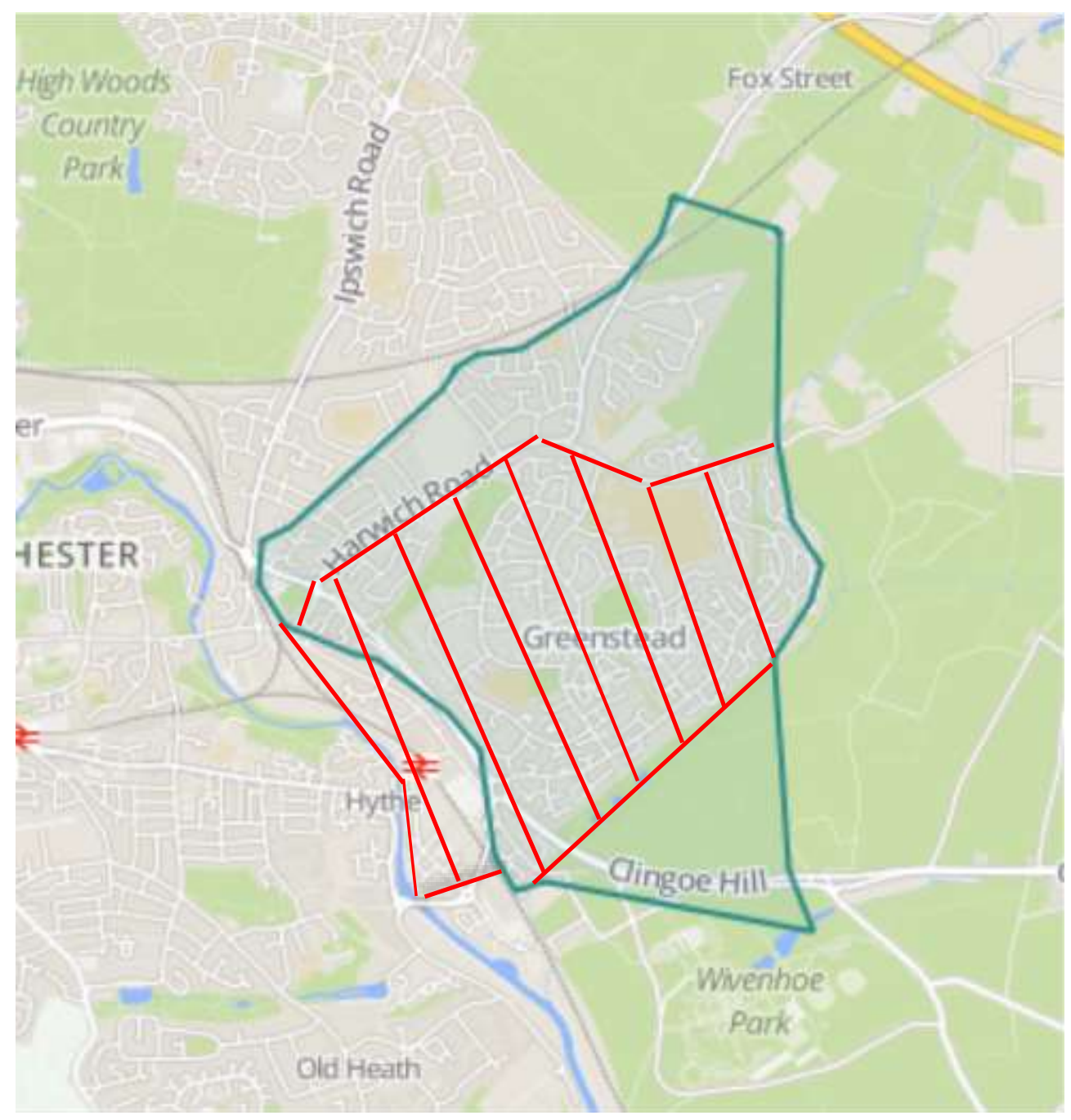

Figure two: Map of the St Andrew's Ward, Colchester bordered in green. The red hatched area is that part of St Andrew's and Harbour wards where the crime rate was differentiated from data collected at ward level. It is also an area where large numbers of students live. 
The $2.22 \%$ of the Clinic's caseload which has assisted the legal needs of small businesses is also low even when taking into account that small businesses are known to be a hard to reach group for legal services generally.

As previously discussed, there is a high student density in the Greenstead area and that part of Hythe which hatched in red in figure one. Many of these will be undergraduate students who will not be resident for large parts of the year during vacations, etc. This in turn has implications for the economic development of the community. It is more difficult to establish a shop, for example, in an area where population numbers are not stable, and significantly decrease for lengthy periods of the calendar year. It also has implications for business advice to start ups in the area.

The percentage of caseload at $0.58 \%$ that is devoted to welfare benefits work seems, at first glance, shockingly low for a clinic operating in an area of relative deprivation. However, the Clinic has only recently marketed itself as having expertise in welfare benefits work. There are also issues in relation to the delivery of the service as there is a Citizens Advice Bureau located in Colchester town centre. This is a well-known and well-established brand for benefits advice work. Again, meeting any unmet need probably means thinking strategically about the service offered. The service offered by bureaux varies, the Essex Law Clinic could probably most effectively address unmet legal need in the area by taking referrals from Citizens Advice to do representation work 
at first-tier Tribunals, which Citizens Advice tends not to do concentrating instead on initial advice and assistance.

The review of the Clinic's clients found a spatial injustice by group, as since its inception in 2008 it has only advised one retired person and, therefore, it appears it is not meeting the legal needs of a group defined by age.

There are several possible reasons for failing to meet the needs of this group. Other studies have shown that different demographic groups use different strategies in response to legal problems with the $65 \mathrm{~s}$ and over amongst the least likely to take action in response to a legal problem of any age group. ${ }^{37}$ It could be cultural: they could be reluctant to be seen to be complaining preferring to take a more stoical approach or they find the idea of accessing services via a university alienating; it could be practical: they find it difficult for a number of reasons such as mobility problems, to come to the university campus to access the Clinic's services; it could simply be that they are unaware of the university's services or aware of them but wrongly assume that they are not eligible to use them. The next stage is to evaluate whether this need can be met through outreach work: going out and holding pop up clinics in the community which will be easier for this age group to access.

This focus on one part of Colchester is intensely local. In order to be a useful part of students' legal education it has to avoid being parochial. We have 
already looked at social relations between the Greenstead and Hythe area, on the one hand, and Wivenhoe, on the other. But what lessons can be learnt from the locality's relations with other parts of the world?

Mapping a local area can be a vehicle for examining issues of global social justice with students, and how 'time-space compression', condensing or eliding spatial and temporal distances, affects different groups in the community and beyond. The University of Essex is international in its outlook with $40 \%$ of its students (over 5,000 people) coming from outside the UK. ${ }^{38}$ On a statistical basis this is likely to be reflected in the composition of the student population of the Greenstead and Hythe areas of Colchester.

It could be argued that this shows a 'progressive sense of place' - a place which is outward looking and positively integrates the global and the local - in that it has relations with other places, and does not feel threatened by them. ${ }^{39}$ These relations benefit the students' home countries who will gain their enhanced skills when they return to work. However, developments in one area will invariably affect another area. Less positively are the immigrant medical workers in the area working at Colchester General Hospital causing shortages in medical centres in their own countries?

\footnotetext{
38 University of Essex 'Key Statistics' (About Us) < https://www.essex.ac.uk/about/university/facts and figures/key statistics.aspx> accessed 20 February 2017

39 Doreen Massey, 'Power geometry and a global sense of place' in Jon Bird, Barry Curtis, Tim Putnam, George Robertson, and Lisa Tickner (eds), Mapping the Futures: Local Cultures, Global Exchange (Routledge 1993) 68
} 
Part Three: Management of a Long-term Educational Unmet Legal Need

\section{Project}

The LawZone Colchester project is intended to be long-term, which will continue after the student advisers, possibly several cohorts of student advisers, have completed their studies. This creates a challenge: how do students have the desired ownership of the project when they will have to relinquish control at some point and another cohort takes over? For these purposes a project is defined as something which 'involves students solving legal problems through the use of strategies and tactics other than litigation. ${ }^{40}$ As has been discussed above, the project has been a collaborative effort between tutor and student adviser. It is submitted that this does not compromise student ownership, but the tutor involvement is a form of guidance and support to enhance the students' work. Students still have ownership as there is a client whose needs the students must address, i.e. the community the Clinic serves.

The various stages of a project have been identified as:

(1) problem identification/definition, (2) gathering evidence,

identifying and exploring alternatives, (4) developing and possibly implementing a strategy for solving the problem, and (5) repeating the

\footnotetext{
$40 \quad$ Anna E. Carpenter, 'Project Model of Clinical Education: Eight Principles to Maximize Student Learning and Social Justice Impact' 20 Clinical L. Rev. 2013-2014, 50
} 
process again if necessary, as problem solving is typically an iterative process. ${ }^{41}$

The scale of the project means that it is overlapping a number of these stages. Stage one has been completed. The problem has been identified as it has arrived at a workable definition of unmet legal need: problems(s) being experienced by the community where legal process is a possible solution and for which a significant identifiable section of the community is experiencing difficulty in accessing advisory services. It has also spatially defined its community as that part of the St Andrews Ward which is south east of Harwich Road and that part of The Hythe bound by the river and major roads.

It is still at stage two, as the project continues to gather evidence. However, sufficient evidence has already been collected to identify two possible groups as not having their needs met: the LGBT+ community and the retired.

Stage four has been partially achieved as strategies have been identified to better meet the needs of the LGBT+ and retired communities by reaching out to them either through outreach activities and/or making it clearer through promotional literature, etc. that services are designed with their needs in mind. At the time of writing, preparations are being made to implement these strategies. However, there is a need to go beyond the paper sources and reach out to the community itself. A stakeholder group would enhance the project

${ }^{41} \quad \mathrm{~N} 40,72$ 
as well as a survey of local residents. This creates skills and development needs for the students who will have to become proficient in survey design. However, there is guidance available for such survey design..$^{42}$ In order to assist with the comparability of data, it is desirable that precedent questions are used unless there are compelling reasons due to local variation to depart from them. ${ }^{43}$ If it is necessary to depart from precedent then this requires expert assistance.

As it is an iterative process then future cohorts of students will repeat various aspects of these stages. Whilst it will not be possible in an ongoing project to alter the definition of what is meant by unmet legal need it will still be possible to identify different communities within the Essex Law Clinic's catchment area. With regard to Stage Two, the collection of socio-economic data is an on-going process as this is collected from clients at each interview, and there is a need to keep up to date with governmental data. The more data collected the richer the picture. It will provide more opportunity to see if the community has changed over time, as well as assessing if there is 'postcode deprivation' or any other reason to think that there is a variation from predictive modelling. There is also further work required in terms of mapping social infrastructure. The project has so far mapped some physical resources. It now needs to identify

$\begin{array}{ll}{ }_{4}^{42} & \text { N 3 } \\ 43 & \text { N 14, } 68\end{array}$


other resources, particularly human resources, such as community leaders, community activists, employers of local inhabitants, etc.

As the stages of the project are iterative, the strategies are the abstract conceptualisation; the experience of implementing strategies has to be kept under review; there needs to be reflection on the experience; which will then go onto create a new experience in the manner of Kolb's experiential learning cycle. ${ }^{44}$

External controls have been established for the next generation of students to work on the project: the work students undertake is confined to any research or activity which furthers understanding of unmet legal need within the jurisdiction of Colchester Borough Council and is within the remit of the Essex Law Clinic.

\section{Conclusions}

Identifying unmet legal need is something which should concern clinics as it undermines the rule of law; it helps clinicians realise 'latent demand'; and it is of assistance to policymakers in their decision making.

It provides students with an opportunity to gain insight into systemic problems facing the communities they serve. They will gain experience of the methodological problems in establishing unmet legal need, as well as

44 David Kolb, Experiential Learning: Experience as the Source of Learning and Development ( $2^{\text {nd }}$ edition, Pearson 2014) 
quantitative and qualitative research methods. It requires working with Big Data but also identifying the limits of the effectiveness of relying on it. They will also be equipped with an awareness of the impact research findings can have.

It is a particularly effective way of maximising student ownership as their experience as digital natives enables them to put forward fresh perspectives and participate in clinic on a basis of equality with tutors and practitioners. However, to work effectively, and to maximise student ownership, the mapping project has to set external controls so that its long-term operation can be broken down into discrete aspects which are achievable within the time that students will be working within the clinic.

In addition to research skills, it develops skills of project management, entrepreneurship, and interdisciplinary practice. It also allows students to examine issues from fresh perspectives. It can enhance their spatial thinking and allows them to see how causes of injustice can be embedded into the architecture of the environment, as well as developing their visual awareness. It embeds them more deeply into their local communities which enhances their understanding of the clients they serve as well as breaking down barriers between the clinic and the community and overcome the risk of the clinic as being seen as something other. 